\title{
An artificial intelligence system reveals liquiritin inhibits SARS- CoV-2 by mimicking type I interferon
}

Jie Zhu ${ }^{1^{*}}$, Yong-Qiang Deng ${ }^{2^{*}}$, Xin Wang ${ }^{1^{*}}$, Xiao-Feng $\mathrm{Li}^{2^{*}}$, Na-Na Zhang2 ${ }^{2}$ Zurui Liu ${ }^{3}$, Bowen Zhang, ${ }^{1}$, Cheng-Feng Qin ${ }^{2, \#}$, Zhengwei Xie ${ }^{1, \#}$

1Peking University International Cancer Institute and Department of Pharmacology, School of Basic Medical Sciences, Peking University, Beijing, China

${ }^{2}$ State Key Laboratory of Pathogen and Biosecurity, Beijing Institute of Microbiology and Epidemiology, Academy of Military Medical Sciences, Beijing, China

${ }^{3}$ Gigaceuticals Co. Ltd., Beijing, China

${ }^{*}$ These authors contributed equally

\# Correspondence:

Zhengwei Xie: xiezhengwei@hsc.pku.edu.cn

Chengfeng Qin: qincf@bmi.ac.cn

\begin{abstract}
The pandemic COVID-19 has spread to all over the world and greatly threatens safety and health of people. COVID-19 is highly infectious and with high mortality rate. As no effective antiviral treatment is currently available, new drugs are urgently needed. We employed transcriptional analysis to uncover potential antiviral drugs from natural products or FDA approved drugs. We found liquiritin significantly inhibit replication of SARS-CoV-2 in Vero E6 cells with $\mathrm{EC}_{50}=2.39 \mu \mathrm{M}$. Mechanistically, we found liquiritin exerts anti-viral function by mimicking type I interferon. Upregulated genes induced by liquiritin are enriched in GO categories including type I interferon signaling pathway, negative regulation of viral genome replication and etc. In toxicity experiment, no death was observed when treated at dose of $300 \mathrm{mg} / \mathrm{kg}$ for a week in ICR mice. All the organ indexes but liver and serum biochemical indexes were normal after treatment. Liquiritin is abundant in licorice tablet ( $\sim .2 \%$ by mass), a traditional Chinese medicine. Together, we recommend liquiritin as a competitive candidate for treating COVID-19. We also expect liquiritin to have a broad and potent antiviral function to other viral pathogens, like HBV, HIV and etc.
\end{abstract}

\section{Introduction}

Began at the end of year 2019, a novel coronavirus named SARS-CoV-2 caused outbreaks of pulmonary diseases (COVID-19) worldwide. It has greatly threatened the public health in global and killed tens-of-thousands of people ${ }^{1}$. By May 2nd, there are $>340,000$ cumulative cases globally, with $>240,000$ deaths. At present, some drugs are considered 
modestly effective in treating COVID-19, including chloroquine and remdesivir. However, the efficacy and safety of these drugs for SARS-CoV-2 pneumonia patients are not conclusive after several clinical trials. Current studies showed controversial effects in different trials ${ }^{2}$. As there is no specific treatment against COVID-19, identifying effective and safe antiviral agents to combat the disease is urgently needed.

Previous strategies for anti-viral drug development mainly focus on blocking receptors or inhibiting proteases. However, boosting the protective ability of the host was rarely considered. Herein, we consider a method to inhibit the gene expression of multiple factors that related to viral replication with one single compound. Previously, the chemical treated cell cultures were measured and analyzed by microarray or L1000 techniques ${ }^{3,4}$. The gene set enrichment analysis (GSEA) or Venn diagram were applied to connect the gene expression profile to up / down gene sets of certain diseases. Such technique, named connectivity map (CMAP) has been applied in screening drugs for obesity ${ }^{5,6}$. We proposed that similar strategy can be applied to inhibit host machinery proteins that supporting the viral replication and to induce genes that blocking the viral replication.

Liquiritin is one of the main flavonoids in Glycyrrhiza uralensis, which acts as an antioxidant and has antidepressant, neuroprotective, anti-inflammatory and therapeutic effects on heart system diseases ${ }^{7-11}$. Liquiritin plays a strong protective effect on vascular endothelial cells in myocardial ischemia-reperfusion injury model ${ }^{11}$. It can also protect smokinginduced lung epithelial cell injury ${ }^{12}$.

Type I interferon (INF) is important cytokines to protect host from viral infection. Almost all human cells can produce INF $\alpha / \beta$, which are the best-defined type I INFs. INFs are able to induce the downstream IFN stimulated genes (ISGs) to inhibit the viral replication, including MX1, PKR, OAS, IFITM, APOBEC1, TRIM and etc ${ }^{13}$.

In present study, we first predicted the efficacy of compounds to inhibit the viral replication. Then, we tested them using Vero E6 cell lines. We found liquiritin is able to inhibit infection of SARS-CoV-2 efficiently with $\mathrm{EC}_{50}=2.39 \mu \mathrm{M}$. Mechanistically, we found liquiritin mimicked type I INF to induce ISGs and thus protect cells from infection. We also evaluated the bioavailability, metabolism and safety of liquiritin.

\section{Results}

\section{Prediction of efficacy against host genes related to viral replication}

To perform GSEA against chemical induced transcriptomes, a gene set is required. In the case of SARS-CoV-2, a reasonable gene set that are enriched in viral processes by analyzing the ACE2-expressed AT2 cells were reported by Zhao et. $\mathrm{al}^{14}$. These genes include TRIM27, IFITM3, TMPRSS2, LAMP1 and etc. The full list is shown in Methods section. We chose the FDA approved drugs and natural products as the compound library (3682 in total). We employed InfinityPhenotype ${ }^{15}$, which is an artificial intelligence based platform, to predict 
efficacy of potential drugs (Figure 1a). InfinityPhenotype takes molecule formula as input and calculate the enrichment score, similar as in CMAP, but only one side is considered. All the scores were plotted in Figure 1b. The top scored compounds are shown in Supp. Table 1. In the natural product list, liquiritin $(-0.32)$ and agnuside $(-0.31)$ have emerged. In FDA approved drugs, we obtained procaterol (-0.23), pibrentasvir (-0.23) and carbocisteine $(-0.21)$. Liquiritin ranks first among all the compounds.

\section{In Vitro verification of the efficacy}

To experimentally verify the predicted results, we measured the effects of these compounds on the virus yield and infection rates of SARS-CoV-2. First, a cytopathic effect (CPE) inhibition assay with only one dose was performed in Vero E6 cells (ATCC-1586) for fast screening. Among the five tested drugs, liquiritin exhibited significant CPE inhibition at $10 \mu \mathrm{M}$ qualitatively. We then employed qRT-PCR to quantify the inhibition and expanded the concentration from 0.1 to $100 \mu \mathrm{M}$. Vero E6 cells were infected with SARSCoV-2 at $100 \mu \mathrm{l}$ median tissue culture infectious dose (TCID50). Notably, liquiritin potently blocked virus infection at low-micromolar concentration $\left(E_{50}=2.39 \mu \mathrm{M}\right.$, Figure 1c).

a

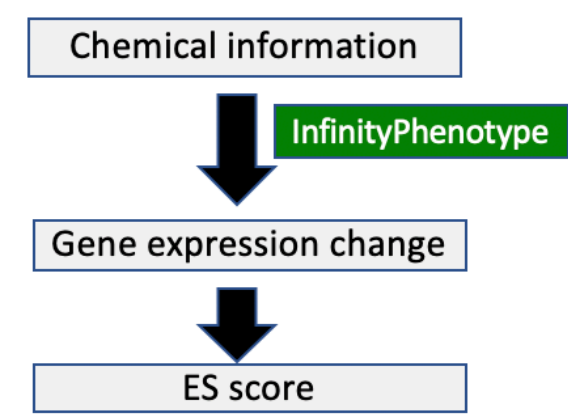

C

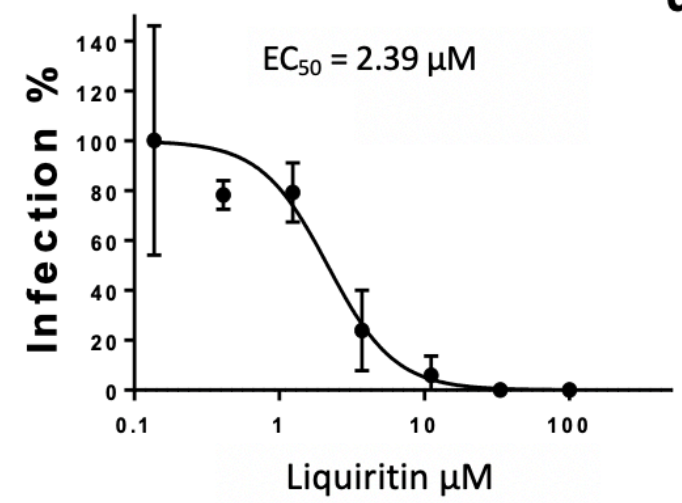

b

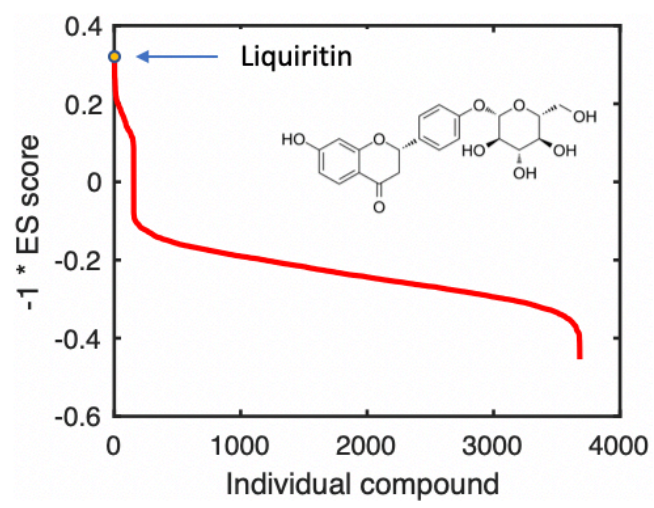

d

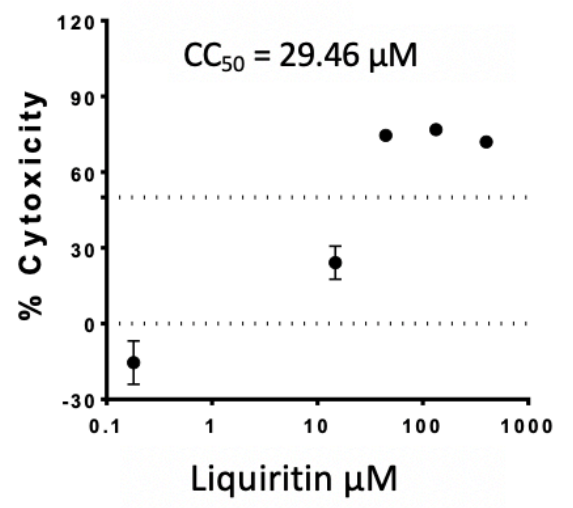

Figure 1 The antiviral activities of the liquiritin against SARS-CoV-2 in vitro.

a) The workflow of the computation of enrichment score (ES). b) The ES score of all compounds. Liquiritin ranks first. c) The antiviral activity of liquiritin in Vero E6 cells (EC50 $=2.39 \mu \mathrm{M}, \mathrm{n}=$ 3 for where error bar is shown). d) Cytotoxicity of the liquiritin to Vero E6 cells was measured by MTS assay. 


\section{Transcriptomic analysis of cell line treated with liquiritin}

The transcriptomic change induced by liquiritin (Figure 2a) in MCF7 cells was reported by $\mathrm{Li}$ et $\mathrm{al}^{4}$. Gene Ontology analysis reveals that the upregulated genes are enriched in the "type I interferon signaling pathway", "negative regulation of viral genome replication", "defense response to virus" and "response to virus" categories (Figure $2 \mathrm{~b}$ ) with $p$-value < $8.26 \mathrm{e}-4,8.29 \mathrm{e}-4,0.0021$ and 0.0039 , respectively. Nine genes in the first category were IFIT1, IFIT3, IFITM1, IFI6, IFI27, OAS3, OAS1, PSMB8 and IRF8. The induced ISGs include MX1, OAS, IFIT, IFITM and etc. as shown in the "negative regulation of viral genome replication" category. IFIT1 and IFIT3 belong to the type I interferon (IFN)-induced protein with tetratricopeptide repeats (IFIT) family and IFITM1 belongs to the IFN-induced transmembrane protein (IFITM) family. Thus, liquiritin exhibits a general anti-viral activity by mimicking the type I IFN. Further, the enrichment analysis of protein-protein interaction networks reveals a significant module composed of nine ISGs (Figure 2d). Other genes in this module indicate potential regulators of these ISGs.

Further, the "inflammatory response" is also enriched in down-regulated genes with $p$ value $<0.015$ (Figure 2c), showing liquiritin reduced inflammatory response. In this category, IL13, IL17B and etc. showed up. This may be beneficial for avoiding the cytokine storm observed in COVID-19.

a

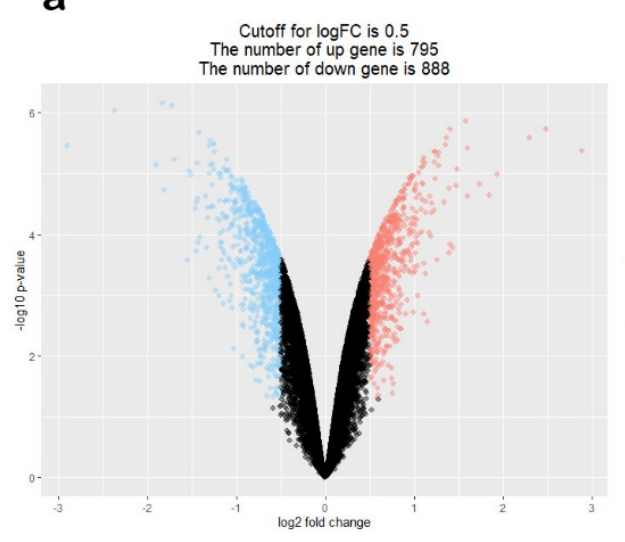

c

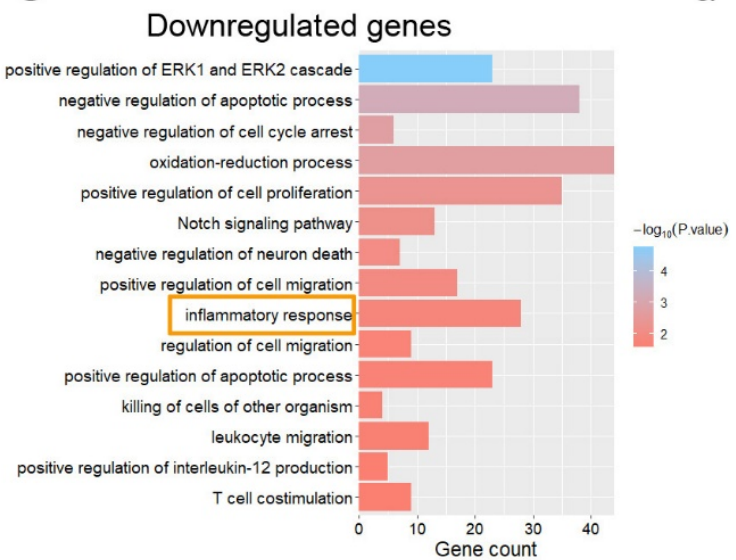

b

d
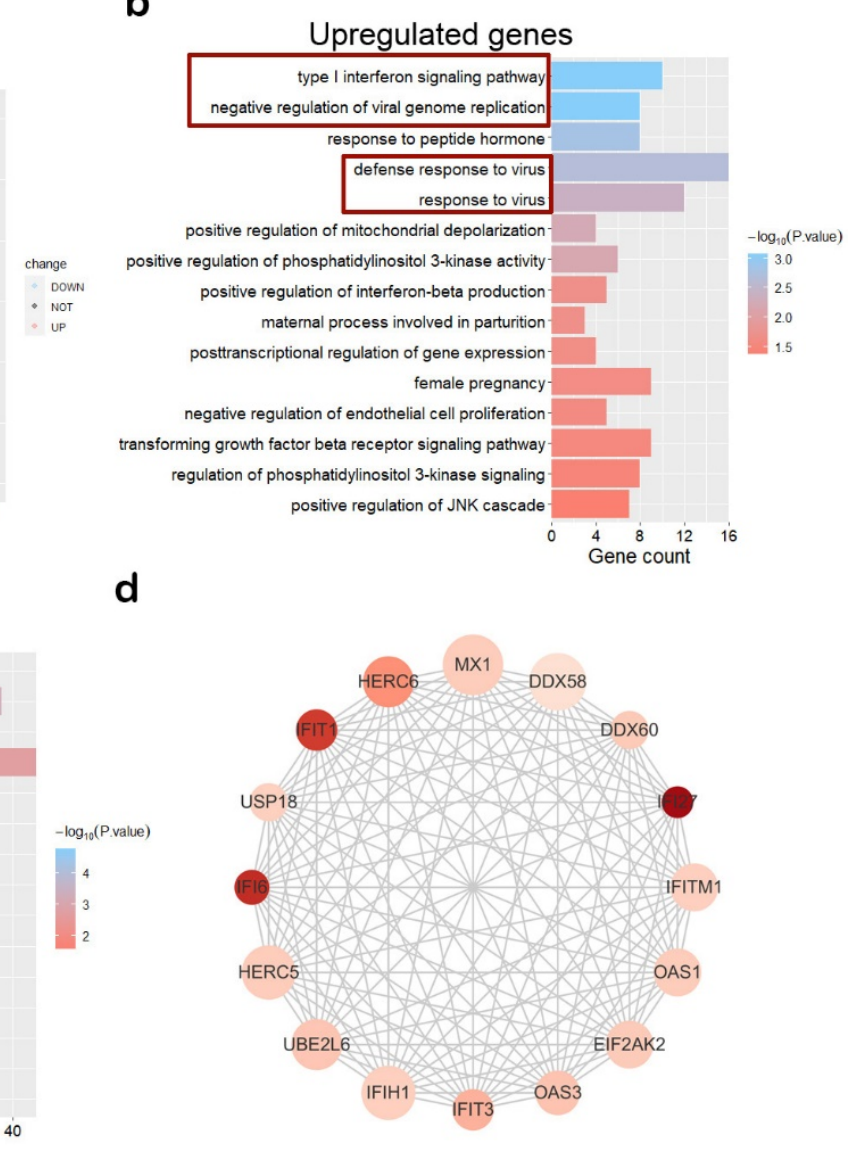
Figure 2 Transcriptomic analysis of cell line treated with liquiritin.

a) Volcano plot of the differentially expressed genes (DEGs) in MCF7 cells treated with liquiritin compared to that in normal cells. Gene Ontology analysis of upregulated genes (b) and that of downregulated genes (c). d) The most significant module of the protein-protein interaction (PPI) network of upregulated genes. Node size is positively related to degree of genes and the gradation of color positively associated with the expression change of this gene.

\section{Liquiritin does not inhibit 3CL pro}

Liu et al. ${ }^{18}$ found derivatives of flavones efficiently inhibit 3CL pro, which is a conserved protease for SARS-CoV-2 replication. Liquiritin is also a derivative of flavones, specifically it is a monosaccharide derivative and a monohydroxyflavanone. It has a mother nucleus structure similar to the compounds found by Liu et al. Though molecule docking showed there might be a binding to 3CL pro, liquiritin didn't show any inhibitory effects to the activity of $3 \mathrm{CL}^{\text {pro }}$ in vitro at $12.5,25.0$ and $50.0 \mu \mathrm{M}$ (data not shown).

\section{Liquiritin is a safe candidate for treating COVID-19}

To evaluate the safety of liquiritin, the cytotoxicity in Vero E6 cells was determined by MTS assay $\left(\mathrm{CC}_{50}=29.46 \mu \mathrm{M}\right.$, Maximal inhibition of cell growth is $70 \%$, as shown in Figure 1d). We further examined the toxicity in vivo. No morality was observed at $150 \mathrm{mg} / \mathrm{kg}$ dose of one-time treatment of liquiritin by intravenous administration during the 14 days monitoring period (Figure 3a). Mice intravenous administration $150 \mathrm{mg} / \mathrm{kg}$ of liquiritin did not manifest any signs of toxicity during this observation period. The body weight, food intake and water intake are shown in Figure $3 b$, c. A continuous treatment for seven days at $300 \mathrm{mg} / \mathrm{kg}$ was also performed. The mortality rate is also zero (Figure 3d). The intake food, body weights were all kept at normal level (Figure 3e, f). As reported in literatures, liquiritin has no significantly cytotoxic effects in L-02, GES-1, IMR-90 and 293T cells with different concentrations $(30,60,90,120$, and $150 \mu \mathrm{M})$ and the MTT assay results confirmed that $345 \mu \mathrm{M}$ liquiritin has no influence on the viability of RA-FLS cells ${ }^{16,17}$.

For both assays shown in Figure 3a, d, we also measured organ and serum biochemical indexes. No significant differences organ indexes (ratio of organ weight to body weight) were observed except liver index compared with the control mice. Meanwhile, levels of glucose, cholesterol, triglyceride, high-density lipoprotein (HDL-C), and low-density lipoprotein (LDL-C) kept normal after liquiritin administration. We observed declined ALT and it may be due to the anti-inflammatory effect of liquiritin. Meanwhile, no abnormality was observed in levels of blood UREA、UA、CK、 $\alpha-\mathrm{HBDH}$, suggesting renal function and heart function were not harmed. Though some relevant index of blood analysis, such as the number of leukocytes, neutrophils and etc., in the control mice and liquiritin-treated mice are different, they are all within the range of reference values, indicating that liquiritin has no obvious toxicity (Supplementary Table 6-9). 

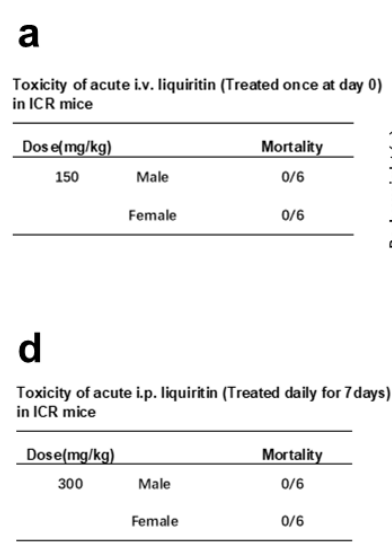
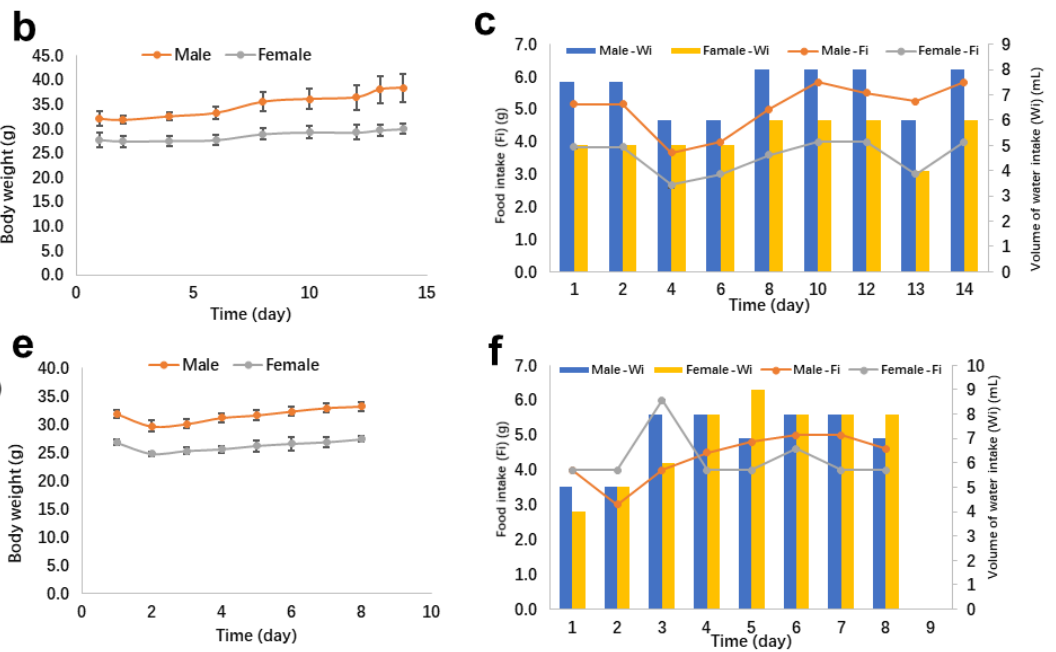

Figure 3 The Toxicity assay for liquiritin in ICR mice.

a) Mortality rate of acute i.v. liquiritin in ICR mice. b, c) Body weight, food intake and water intake at $150 \mathrm{mg} / \mathrm{kg}$ dose of one-time treatment of liquiritin by intravenous administration during the 14 days monitoring period in ICR mice. d) Mortality rate of acute i.p. liquiritin in ICR mice. e, f) Body weight, food intake and water intake at $300 \mathrm{mg} / \mathrm{kg}$ dose of liquiritin by i.p. administration for seven days in ICR mice.

\section{Pharmacokinetics survey of liquiritin}

To evaluate the pharmacokinetics of liquiritin, we searched literatures and found the pharmacokinetic data of mixtures containing liquiritin (Supp. Table 2). The corresponding dose of liquiritin is range from 225 to $44,000 \mathrm{ug} / \mathrm{kg}$, the $C_{\max }$ in serum is range from 0.064 to $2.3 \mu \mathrm{M}$. The $\mathrm{T}_{\max }$ is range from 0.25 to 0.6 hours and $\mathrm{T}_{1 / 2}$ is range from 1.9 to 11.63 hours. As the bioavailability is low and degradation is fast, we suggest an intravenous or inhalation administration for liquirtin.

\section{Discussion}

To find drugs that may cure COVID-19, we adopted a different strategy by analyzing transcriptional changes induced by various compounds. We found that liquiritin is highly effective in the inhibition of SARS-CoV-2 infection in vitro compared to other SARS-CoV2 drugs reported in vitro (Supp. Table 3). Since liquiritin is also one of the main ingredients of compound licorice tablets, we speculate that it is safe. Indeed, it didn't show toxicity and side effects in two independent experiments. In summary, we suggest that liquiritin should be assessed in human patients suffering from the COVID-19.

Mechanistically, we found liquiritin induced the expression of anti-viral genes. GO analysis revealed that "type I INF signaling pathway" was activated. We thus proposed that liquiritin may mimic type I INF to inhibit the viral replication. Vero E6 cell line we used here lack IFNB1 gene and cannot synthesize interferon. However, Vero E6 cells contain the trans-acting factors needed for human beta interferon ${ }^{20}$. It's still responsive to 
human INF. Thus, liquiritin acted through downstream of INF synthesis.

We also surveyed the literatures for the targets of liquiritin. It's reported that liquiritin, a flavonoid isolated from Glycyrrhiza, is a potent and competitive AKR1C1 inhibitor with IC 50 of $0.62 \mu \mathrm{M}, 0.61 \mu \mathrm{M}$, and 3.72 $\mu \mathrm{M}$ for AKR1C1, AKR1C2 and AKR1C3, respectively ${ }^{19}$. Whether AKR1 is the major target for liquiritin's anti-viral activity is unclear. Further experiments need to be carried out.

So far, there are no first principles to precisely simulate the intrinsic interactions of cells. One alternative solution is to use the measured data to overcome the difficulty of complex systems. Deep neural network offers an option to empirically fit high dimensional data. InfinityPhenotype we employed here is based on transcriptional change induced by compounds. Such framework treated a broad range of interactions inside the cells, from ligand-protein interaction to transcriptional regulations, as well as other hidden interactions, as a black box. It offers us an opportunity to predict the efficacy of compounds in a precise manner.

To test if other gradients in liquorice inhibit the viral replication, we also tested liquiritigenin and glycyrrhizic acid in Vero E6 cells. Neither of them showed inhibitory effect (data not shown). Further animal test, transcriptional measurement with virus in Vero E6 cells and in mice are still ongoing. Because type I interferon is responsive to most viruses that infect vertebrate, we expect liquiritin having a broad and potent antiviral function to other viral pathogens, like HBV, HIV and etc.

\section{Methods}

\section{Virus and Cells}

The stock of SARS-CoV-2 strain BetaCoV/wuhan/AMMS01/2020 was originally isolated from a patient returning from Wuhan. The virus was amplified and titerated by standard plaque forming assay on Vero cells. All experiments involving infectious SARS-CoV-2 were performed in biosafety level 3 (BSL3) containment laboratory in AMMS. Vero cell were purchased from ATCC (Cat\# CCL-81) and cultured in DMEM supplemented with $10 \%$ FBS at $37^{\circ} \mathrm{C}$.

\section{Prediction of efficacy}

The full list of genes used for enrichment analysis (GSEA) includes SLC1A5, CXADR, CAV2, NUP98, CTBP2, GSN, HSPA1B, STOM, RAB1B, HACD3, ITGB6, IST1, NUCKS1, TRIM27, APOE, SMARCB1, UBP1, CHMP1A, NUP160, HSPA8, DAG1, STAU1, ICAM1, CHMP5, DEK, VPS37B, EGFR, CCNK, PPIA, IFITM3, PPIB, TMPRSS2, UBC, LAMP1 and CHMP3. Kolmogorov-Smirnov (KS) test is used to evaluate the distribution of query genes in reference list. The gene expression fold change was calculated by InfinityPhenotype platform and used to make the rank list (>10,000 in this case). The ES score for one gene set 
is defined as:

$$
\mathrm{ES}=\max _{j=1 \text { to } t}\left[\frac{j}{t}-\frac{V(j)}{n}\right]
$$

where $t$ is the number of genes in the targeted gene set, $n$ is the number of genes in full gene expression profile, $\mathrm{V}(\mathrm{j})$ is the rank of a specific gene in the rank list.

\section{Cytotoxicity assay}

The cytotoxicity of the tested drugs on Vero Cell were determined by MTS cell proliferation assays (Promega, USA), according to manufacturer's protocol. Briefly, $\sim 1 \times 104$ cells were seeded into a $96-$-well plate and incubated for $20-24 \mathrm{~h}$ at $37^{\circ} \mathrm{C}$. The media was removed, and $100 \mu \mathrm{l}$ of media containing decreasing concentrations of antiviral compound were added to the wells. All determinations were performed in triplicate. After 4 days incubation at $37^{\circ} \mathrm{C}$, MTS assays were performed according to manufacturers' protocols. A microtiter plate reader (SYNERGY HTX, BioTek Instruments) with a $490 \mathrm{~nm}$ filter was used to record absorbance. After adjusting the absorbance for background and comparing to untreated controls, the cytotoxic concentration CC50 was calculated using a sigmoidal nonlinear regression function to fit the dose-response curve using the GraphPad Prism 7.0 software.

\section{The in vitro antiviral activity.}

The in vitro antiviral efficacy of the tested drug on Vero E6 Cell was performed as we previously described [Jin, et al., 2020]. Briefly, $\sim 1 \times 104$ cells were seeded into a 96-well plate and incubated for $20-24 \mathrm{~h}$ at $37^{\circ} \mathrm{C}$. Cells were pre-treated with the indicated antivirals $(10 \mu \mathrm{M})$ for $1 \mathrm{~h}$, and the virus (MOI of 0.01 ) was subsequently added to allow infection for $2 \mathrm{~h}$. Then, the virus-drug mixture was removed and cells were further cultured with fresh drug-containing medium. At 48 h p.i., viral RNA copy in supernatants were quantified by qRT-PCR assays with the SARS-CoV-2-specific primers.

\section{Toxicity study in ICR mice}

ICR mice were used to test the in vivo safety of liquiritin. Thirty-Six ICR male and female mice were purchased from the Peking University Animal Department. The animals were housed in a temperature-controlled animal room $\left(24 \pm 2{ }^{\circ} \mathrm{C}\right)$ with a relative humidity of 60 $80 \%$. All mice were fasted overnight but given water ad libitum prior to dosage. Animals were divided into two groups with 6 males and 6 females at random. Liquiritin was dissolved in 10\% DMSO/40\% PEG400/50\% Saline and administered i.v. once at doses of $150 \mathrm{mg} / \mathrm{kg}$, and administered i.p. once a day for 10 days at doses of $300 \mathrm{mg} / \mathrm{kg}$. Their general behavior, signs of toxicity, body weights and mortality were recorded after the administration of liquiritin. Animals were killed by excessive anesthesia. Gross necropsy, weighing, calculation of organ index (brain, heart, lung, liver, kidney, adrenal gland, thymus, spleen, testis, epididymis, ovary, uterus, thyroid), pathological examination of the organs was carried out afterwards. The blood sample was analysis by blood analyzer 


\section{HEMAVET 950FS.}

\section{Transcriptional analysis}

Microarray data on gene expression (GSE85871) was downloaded from Gene Expression Omnibus (GEO). The DEGs between normal and liquirintin-treated MCF7 cells were also screened by the limma package. $|\log 2 \mathrm{FC}| \geq 0.5$, adjust $\mathrm{p}$-value $<0.05$ were considered statistically significant for the DEGs. To elucidate potential biological process associated with the DEGs, we performed GO enrichment analysis utilizing the Database for Annotation, Visualization and Integrated Discovery (DAVID). p-value $<0.05$ was defined as the cut-off criteria. The upregulated DEGs were mapped to STRING to evaluate the PPI information and set confidence score $>0.4$ as the cut-off standard. Cytoscape was used to visualize the PPI network, a practical open-source software tool for the visual exploration of biomolecule interaction networks consisting of protein, gene and other types of interaction.

\section{Enzyme Inhibition Assay}

A colorimetric substrate Thr-Ser-Ala-Val-Leu-Gln-pNA (GL Biochemistry Ltd) and assay buffer (40 mM PBS, $100 \mathrm{mM} \mathrm{NaCl}, 1 \mathrm{mM}$ EDTA, 0.1\% Triton 100, pH 7.3) was used for the inhibition assay. Stock solutions of the inhibitor were prepared with 100\% DMSO. The 100 $\mu \mathrm{l}$ reaction systems in assay buffer contain $0.5 \mu \mathrm{M}$ protease and $5 \%$ DMSO or inhibitor to the final concentration. First, dilute SARS-CoV-2 3CLpro with assay buffer to the desired concentration. $5 \mu \mathrm{l}$ DMSO or inhibitor at various concentrations was pre-incubated with $85 \mu \mathrm{l}$ diluted SARS-CoV-2 3CLpro for $30 \mathrm{~min}$ at room temperature. And then add $10 \mu \mathrm{l} 2$ $\mathrm{mM}$ substrate Thr-Ser-Ala-Val-Leu-Gln-pNA (dissolved in water) into above system to final concentration of $200 \mu \mathrm{M}$ to initiate the reaction. Increase in absorbance at $390 \mathrm{~nm}$ was recorded for $20 \mathrm{~min}$ at interval of $30 \mathrm{~s}$ with a kinetics mode program using a plate reader (Synergy, Biotek). The percent of inhibition was calculated by $V_{i} / V_{0}$, where $V_{0}$ and $V_{i}$ represent the mean reaction rate of the enzyme incubated with DMSO or compounds. IC50 was fitted with Hill function.

Author Contributions: All authors contributed to the work presented in this paper. J. Z. \& W. K. performed the statistical analysis, Z. L. and Z. X performed the efficacy prediction, Y. D., X. L, and N. Z measured the anti-viral activity and performed the analysis. B. Z. performed docking, J. Z. performed the literature review. Z. X \& J. Z. wrote the paper. Z. X \& C. Q. supervised the team.

Acknowledgement: We thank Hongbo Liu and Luhai Lai for the help of 3CLpro assay. Z.W.X was supported by National key research and development program of China (2018YFA0900200), National Natural Science Foundation of China Grants (31771519) and Beijing Natural Science Foundation (5182012). C.F.Q. was supported by the National Science Fund for Distinguished Young Scholar (No. 81925025), and the Innovative Research Group (No. 81621005) from the NSFC, and the Innovation Fund for Medical Sciences (No.2019-I2M-5049) from the Chinese Academy of Medical Sciences. 


\section{REFERENCES}

1. Zhu, N., et al. A Novel Coronavirus from Patients with Pneumonia in China, 2019. $N$ Engl J Med 382, 727-733 (2020).

2. Grein, J., et al. Compassionate Use of Remdesivir for Patients with Severe Covid-19. N Engl J Med (2020).

3. Subramanian, A., et al. A Next Generation Connectivity Map: L1000 Platform and the First 1,000,000 Profiles. Cell 171, 1437-1452 e1417 (2017).

4. Lv, C., et al. The gene expression profiles in response to 102 traditional Chinese medicine (TCM) components: a general template for research on TCMs. Sci Rep 7, 352 (2017).

5. Liu, J., Lee, J., Salazar Hernandez, M.A., Mazitschek, R. \& Ozcan, U. Treatment of obesity with celastrol. Cell 161, 999-1011 (2015).

6. Lee, J., et al. Withaferin A is a leptin sensitizer with strong antidiabetic properties in mice. Nat Med 22, 1023-1032 (2016).

7. Whorwood, C.B., Sheppard, M.C. \& Stewart, P.M. Licorice inhibits 11 betahydroxysteroid dehydrogenase messenger ribonucleic acid levels and potentiates glucocorticoid hormone action. Endocrinology 132, 2287-2292 (1993).

8. Tamir, S., et al. Estrogenic and antiproliferative properties of glabridin from licorice in human breast cancer cells. Cancer Res 60, 5704-5709 (2000).

9. Hatano, T., et al. Phenolic constituents of licorice. VIII. Structures of glicophenone and glicoisoflavanone, and effects of licorice phenolics on methicillin-resistant Staphylococcus aureus. Chem Pharm Bull (Tokyo) 48, 1286-1292 (2000).

10. Takahashi, T., et al. Isoliquiritigenin, a flavonoid from licorice, reduces prostaglandin E2 and nitric oxide, causes apoptosis, and suppresses aberrant crypt foci development. Cancer Sci 95, 448-453 (2004).

11. Sun, Y.X., et al. Neuroprotective effect of liquiritin against focal cerebral ischemia/reperfusion in mice via its antioxidant and antiapoptosis properties. J Asian Nat Prod Res 12, 1051-1060 (2010).

12. Guan, Y., et al. Protective effects of liquiritin apioside on cigarette smoke-induced lung epithelial cell injury. Fundam Clin Pharmacol 26, 473-483 (2012).

13. McNab, F., Mayer-Barber, K., Sher, A., Wack, A. \& O'Garra, A. Type I interferons in infectious disease. Nat Rev Immunol 15, 87-103 (2015).

14. Yu Zhao, Z.Z., Yujia Wang, Yueqing Zhou, Yu Ma, Wei Zuo. Single-cell RNA expression profiling of ACE2, the putative receptor of Wuhan 2019-nCov bioRxiv preprint (2020).

15. Xie., e.a. InfinityPhenotype. To be published.

16. Zhai, K.F., et al. Liquiritin from Glycyrrhiza uralensis Attenuating Rheumatoid Arthritis via Reducing Inflammation, Suppressing Angiogenesis, and Inhibiting MAPK Signaling Pathway. J Agric Food Chem 67, 2856-2864 (2019).

17. Wang, J.R., et al. Liquiritin inhibits proliferation and induces apoptosis in HepG2 hepatocellular carcinoma cells via the ROS-mediated MAPK/AKT/NF-kappaB 
signaling pathway. Naunyn Schmiedebergs Arch Pharmacol (2020).

18. Hongbo Liu, et.al. Scutellaria baicalensis extract and baicalein inhibit replication of SARS-CoV-2 and its 3C-like protease in vitro . bioRxiv preprint (2020).

19. Zeng, C., et al. Liquiritin, as a Natural Inhibitor of AKR1C1, Could Interfere With the Progesterone Metabolism. Front Physiol 10, 833 (2019).

20. Mosca, J.D. \& Pitha, P.M. Transcriptional and posttranscriptional regulation of exogenous human beta interferon gene in simian cells defective in interferon synthesis. Mol Cell Biol 6, 2279-2283 (1986). 


\section{Supplementary Table 1 Results of InfinityPhenotype platform screening}

\begin{tabular}{cccc}
\hline ID & Name & Drug Groups & score \\
\hline T7S0344 & Liquiritin & $\begin{array}{c}\text { natural } \\
\text { product }\end{array}$ & -0.315809062 \\
& & natural & \\
T3S1363 & Agnuside & product & -0.308751956 \\
& & $\begin{array}{c}\text { approved; } \\
\text { investigational }\end{array}$ & -0.233934229 \\
DB01366 & Procaterol & approved; & -0.2277026 \\
& & investigational & \\
DB13878 & Pibrentasvir & & \\
& & approved; & -0.212099668 \\
& & investigational & \\
\hline
\end{tabular}




\section{Supplementary Table 2 Pharmacokinetic Data of Mixtures Containing Liquiritin}

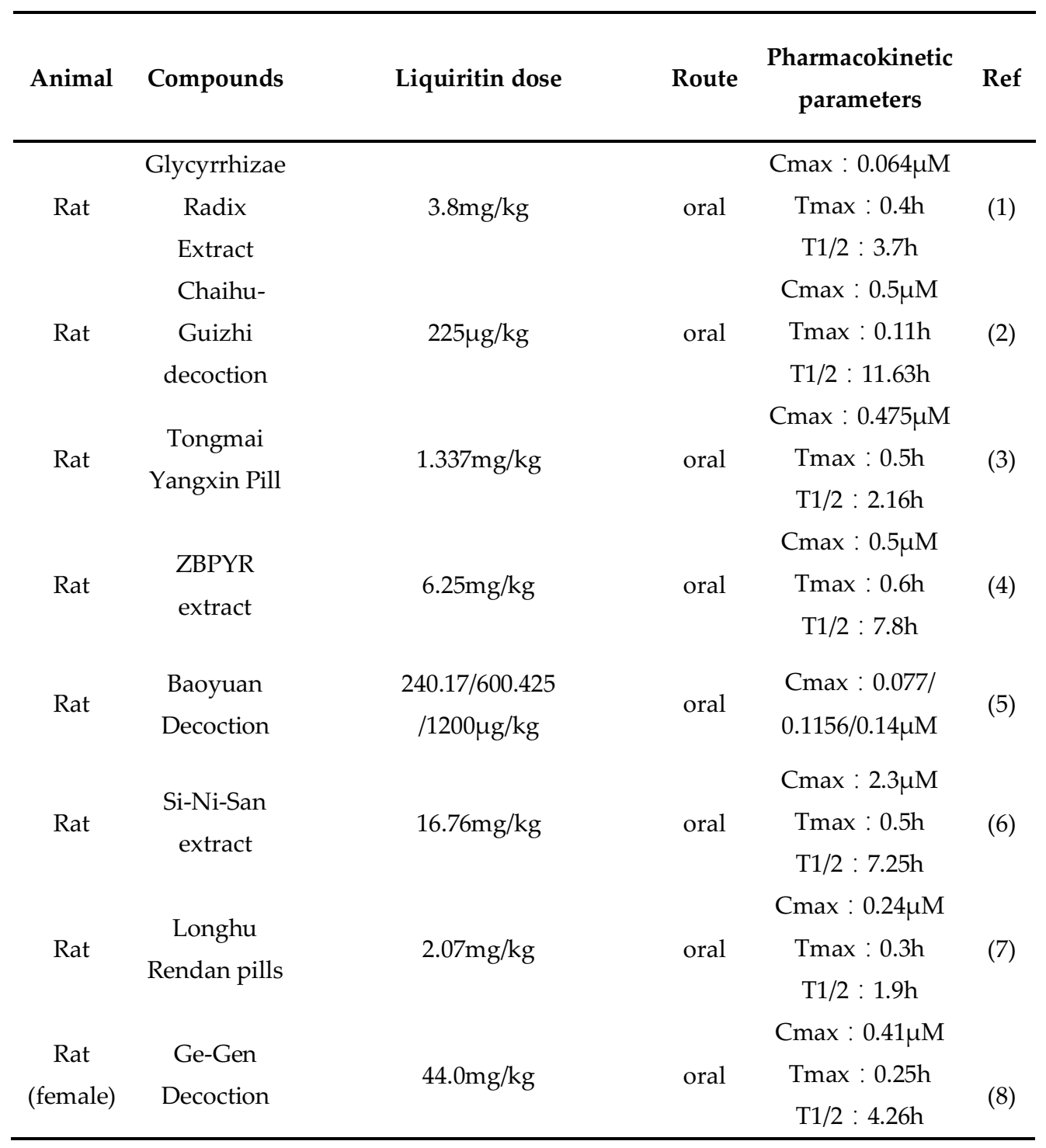

\section{Supplementary Table 2 REFERENCES}

1. Han, Y.J., Kang, B., Yang, E.J., Choi, M.K. \& Song, I.S. Simultaneous Determination and Pharmacokinetic Characterization of Glycyrrhizin, Isoliquiritigenin, Liquiritigenin, and Liquiritin in Rat Plasma Following Oral Administration of Glycyrrhizae Radix Extract. Molecules 24(2019).

2. Li, Z., et al. Simultaneous quantification of fifteen compounds in rat plasma by LCMS/MS and its application to a pharmacokinetic study of Chaihu-Guizhi decoction. J Chromatogr B Analyt Technol Biomed Life Sci 1105, 15-25 (2019).

3. Shen, J., et al. Development of a HPLC-MS/MS Method to Determine 11 Bioactive Compounds in Tongmai Yangxin Pill and Application to a Pharmacokinetic Study in Rats. Evid Based Complement Alternat Med 2018, 6460393 (2018). 
4. Zhang, L., Xu, H. \& Zhan, L. Pharmacokinetic Assessments of Liquiritin, Protocatechuic Aldehyde and Rosmarinic Acid in Rat Plasma by UPLC-MS-MS After Administration of ZibuPiyin Recipe. J Chromatogr Sci 56, 139-146 (2018).

5. Lu, Y.Y., et al. Pharmacokinetics study of 16 representative components from Baoyuan Decoction in rat plasma by LC-MS/MS with a large-volume direct injection method. Phytomedicine 57, 148-157 (2019).

6. Li, T., et al. Simultaneous quantification of paeoniflorin, nobiletin, tangeretin, liquiritigenin, isoliquiritigenin, liquiritin and formononetin from Si-Ni-San extract in rat plasma and tissues by liquid chromatography-tandem mass spectrometry. Biomed Chromatogr 27, 1041-1053 (2013).

7. Wang, T., et al. Simultaneous quantification of catechin, epicatechin, liquiritin, isoliquiritin, liquiritigenin, isoliquiritigenin, piperine and glycyrrhetinic acid in rat plasma by HPLC-MS/MS: application to a pharmacokinetic study of Longhu Rendan pills. Biomed Chromatogr 30, 1166-1174 (2016).

8. Yan, Y., et al. Simultaneous determination of puerarin, daidzin, daidzein, paeoniflorin, albiflorin, liquiritin and liquiritigenin in rat plasma and its application to a pharmacokinetic study of Ge-Gen Decoction by a liquid chromatography-electrospray ionization-tandem mass spectrometry. J Pharm Biomed Anal 95, 76-84 (2014). 


\section{Supplementary Table 3 Against SARS-CoV-2 drugs reported in vitro and Liquiritin}

\begin{tabular}{|c|c|c|c|}
\hline Number & Drug & EC50 & Ref. \\
\hline 1 & Remdesivir & $0.77 \mu \mathrm{M}$ & (1) \\
\hline 2 & Hydroxychloroquine & $0.72 \mu \mathrm{M}$ & (2) \\
\hline 3 & Chloroquine & $1.13 \mu \mathrm{M}$ & (1) \\
\hline 4 & Camostat mesylate & $1 \mu \mathrm{M}$ & (3) \\
\hline 5 & Nitazoxanide & $2.12 \mu \mathrm{M}$ & (1) \\
\hline 6 & Liquiritin & $2.39 \mu \mathrm{M}$ & $\begin{array}{l}\text { This } \\
\text { study }\end{array}$ \\
\hline 7 & Ebselen & $4.67 \mu \mathrm{M}$ & (4) \\
\hline 8 & CVL218 & $5.12 \mu \mathrm{M}$ & (5) \\
\hline 7 & Nafamostat & $22.5 \mathrm{uM}$ & (1) \\
\hline 10 & Terifunomide & $26.06 \mu \mathrm{M}$ & (6) \\
\hline 11 & Favipiravir & $61.88 \mathrm{uM}$ & (1) \\
\hline 12 & Leflunomide & $63.56 \mu \mathrm{M}$ & (6) \\
\hline 13 & Penciclovir & $95.96 \mathrm{uM}$ & (1) \\
\hline 14 & Ribavirin & $109.5 \mathrm{uM}$ & (1) \\
\hline
\end{tabular}

\section{Supplementary Table 3 REFERENCES}

1. Wang, M., et al. Remdesivir and chloroquine effectively inhibit the recently emerged novel coronavirus (2019-nCoV) in vitro. Cell Res 30, 269-271 (2020).

2. Yao, X., et al. In Vitro Antiviral Activity and Projection of Optimized Dosing Design of Hydroxychloroquine for the Treatment of Severe Acute Respiratory Syndrome Coronavirus 2 (SARS-CoV-2). Clin Infect Dis (2020).

3. Hoffmann, M., et al. SARS-CoV-2 Cell Entry Depends on ACE2 and TMPRSS2 and Is Blocked by a Clinically Proven Protease Inhibitor. Cell 181, 271-280 e278 (2020). 
4. Jin, Z., et al. Structure of M(pro) from COVID-19 virus and discovery of its inhibitors. Nature (2020).

5. Y.G., et al. A data-driven drug repositioning framework discovered a potential therapeutic agent targeting COVID-19. bioRxiv preprint (2020).

6. R.X., et al. Novel and potent inhibitors targeting DHODH, a rate-limiting enzyme in de novo pyrimidine biosynthesis, are broad-spectrum antiviral against RNA viruses including newly emerged coronavirus SARS-CoV-2 bioRxiv preprint (2020). 


\section{Supplementary Table 4 : GO analysis of upregulated genes}

\begin{tabular}{|c|c|c|c|}
\hline Term & Count & $\%$ & PValue \\
\hline GO:0060337 type I interferon signaling pathway & 10 & 0.009291 & $8.26 \mathrm{E}-04$ \\
\hline GO:0045071 negative regulation of viral genome replication & 8 & 0.007433 & 8.29E-04 \\
\hline GO:0043434 response to peptide hormone & 8 & 0.007433 & 0.001488 \\
\hline GO:0051607 defense response to virus & 16 & 0.014866 & 0.002137 \\
\hline GO:0009615 response to virus & 12 & 0.011149 & 0.003902 \\
\hline $\begin{array}{l}\text { GO:0051901 positive regulation of mitochondrial } \\
\text { depolarization }\end{array}$ & 4 & 0.003716 & 0.005847 \\
\hline $\begin{array}{l}\text { GO:0043552 positive regulation of phosphatidylinositol 3- } \\
\text { kinase activity }\end{array}$ & 6 & 0.005575 & 0.006636 \\
\hline $\begin{array}{c}\text { GO:0032728 positive regulation of interferon-beta } \\
\text { production }\end{array}$ & 5 & 0.004646 & 0.020022 \\
\hline GO:0060137 maternal process involved in parturition & 3 & 0.002787 & 0.020706 \\
\hline $\begin{array}{c}\text { GO:0010608 posttranscriptional regulation of gene } \\
\text { expression }\end{array}$ & 4 & 0.003716 & 0.022911 \\
\hline GO:0007565 female pregnancy & 9 & 0.008362 & 0.023305 \\
\hline $\begin{array}{l}\text { GO:0001937 negative regulation of endothelial cell } \\
\text { proliferation }\end{array}$ & 5 & 0.004646 & 0.025488 \\
\hline $\begin{array}{c}\text { GO:0007179 transforming growth factor beta receptor } \\
\text { signaling pathway }\end{array}$ & 9 & 0.008362 & 0.027777 \\
\hline $\begin{array}{l}\text { GO:0014066 regulation of phosphatidylinositol 3-kinase } \\
\text { signaling }\end{array}$ & 8 & 0.007433 & 0.032987 \\
\hline GO:0046330 positive regulation of JNK cascade & 7 & 0.006504 & 0.041505 \\
\hline
\end{tabular}




\section{Supplementary Table 5 : GO analysis of downregulated genes}

\begin{tabular}{llll}
\hline Term & Count & $\%$ & PValue \\
\hline GO:0070374 positive regulation of ERK1 and ERK2 cascade & 23 & 0.019502 & $1.65 \mathrm{E}-05$ \\
GO:0043066 negative regulation of apoptotic process & 38 & 0.032221 & $5.22 \mathrm{E}-04$ \\
GO:0071157 negative regulation of cell cycle arrest & 6 & 0.005087 & 0.001725 \\
GO:0055114 oxidation-reduction process & 44 & 0.037308 & 0.00186 \\
GO:0008284 positive regulation of cell proliferation & 35 & 0.029677 & 0.004883 \\
GO:0007219 Notch signaling pathway & 13 & 0.011023 & 0.006354 \\
GO:1901215 negative regulation of neuron death & 7 & 0.005935 & 0.009122 \\
GO:0030335 positive regulation of cell migration & 17 & 0.014414 & 0.010436 \\
GO:0006954 inflammatory response & 28 & 0.023741 & 0.015459 \\
GO:0030334 regulation of cell migration & 9 & 0.007631 & 0.019467 \\
GO:0043065 positive regulation of apoptotic process & 23 & 0.019502 & 0.020164 \\
GO:0031640 killing of cells of other organism & 4 & 0.003392 & 0.023776 \\
GO:0050900 leukocyte migration & 12 & 0.010175 & 0.024075 \\
GO:0032735 positive regulation of interleukin-12 production & 5 & 0.00424 & 0.025538 \\
GO:0031295 T cell costimulation & 9 & 0.007631 & 0.025874 \\
\hline
\end{tabular}


Supplementary Table 6 : Body weight, organ index, blood chemistry and blood analysis in control or liquiritin-treated male mice by intravenous injection.

\begin{tabular}{|c|c|c|}
\hline & Control-male & Liquiritin-male \\
\hline Body weight, $g$ & $36.433 \pm 0.669$ & $38.650 \pm 1.206$ \\
\hline Brain index, $\%$ & $1.163 \pm 0.050$ & $1.228 \pm 0.043$ \\
\hline Thyroid index, \% & $0.693 \pm 0.009$ & $0.618 \pm 0.018$ \\
\hline Lungs index, $\%$ & $0.557 \pm 0.037$ & $0.512 \pm 0.008$ \\
\hline Thymus index, \% & $0.190 \pm 0.040$ & $0.163 \pm 0.011$ \\
\hline Heart index, \% & $0.430 \pm 0.012$ & $0.412 \pm 0.017$ \\
\hline Liver index, \% & $4.413 \pm 0.217$ & $3.590 \pm 0.102^{* *}$ \\
\hline Spleen index, \% & $0.327 \pm 0.026$ & $0.235 \pm 0.024^{*}$ \\
\hline Pancreas index, \% & $0.630 \pm 0.069$ & $0.530 \pm 0.023$ \\
\hline Kidney index, \% & $1.393 \pm 0.057$ & $1.437 \pm 0.044$ \\
\hline Testis index, \% & $0.707 \pm 0.020$ & $0.613 \pm 0.057$ \\
\hline Epididymis index, \% & $0.173 \pm 0.022$ & $0.168 \pm 0.008$ \\
\hline Stomach index, \% & $0.723 \pm 0.048$ & $0.620 \pm 0.018^{*}$ \\
\hline Bladder index, \% & $0.083 \pm 0.018$ & $0.078 \pm 0.003$ \\
\hline ALT U/L & $64.067 \pm 17.767$ & $59.717 \pm 8.245$ \\
\hline AST U/L & $132.4 \pm 48.461$ & $99.734 \pm 7.371$ \\
\hline GLU-God mmol/L & $7.947 \pm 0.731$ & $4.757 \pm 0.623^{*}$ \\
\hline TC mmol/L & $3.570 \pm 0.217$ & $3.920 \pm 0.284$ \\
\hline TG mmol/L & $1.047 \pm 0.217$ & $1.180 \pm 2.295$ \\
\hline $\mathrm{TP} \mathrm{g} / \mathrm{L}$ & $54.700 \pm 3.308$ & $56.150 \pm 2.295$ \\
\hline ALB g/L & $27.867 \pm 0.578$ & $30.85 \pm 0.746^{*}$ \\
\hline UA umol/L & $158.800 \pm 30.175$ & $76.067 \pm 9.691^{*}$ \\
\hline UREA mmol/L & $2.197 \pm 0.082$ & $2.098 \pm 0.064$ \\
\hline $\mathrm{CK} \mathrm{U/L}$ & $464.467 \pm 138.376$ & $381.7 \pm 37.722$ \\
\hline$\alpha-\mathrm{HBDH} \mathrm{U} / \mathrm{L}$ & $31.933 \pm 9.831$ & $34.2 \pm 3.569$ \\
\hline HDL-C mmol/L & $3.133 \pm 0.188$ & $3.178 \pm 0.270$ \\
\hline LDL-C mmol/L & $0.370 \pm 0.062$ & $0.460 \pm 0.024$ \\
\hline LDH U/L & $329.433 \pm 0.062$ & $343.967 \pm 31.700$ \\
\hline ALP U/L & $3.167 \pm 0.584$ & $3.617 \pm 0.101$ \\
\hline T-Bil umol/L & $1.933 \pm 0.192$ & $1.938 \pm 0.098$ \\
\hline Number of leukocytes $\left({ }^{*} 103 / \mathrm{UL}\right)$ & $5.067 \pm 1.012$ & $4.617 \pm 0.283$ \\
\hline Number of neutrophils $\left({ }^{*} 103 / \mathrm{UL}\right)$ & $1.407 \pm 0.234$ & $1.072 \pm 0.091$ \\
\hline Lymphocyte count $\left({ }^{*} 103 / \mathrm{UL}\right)$ & $3.367 \pm 0.769$ & $3.245 \pm 0.205$ \\
\hline Number of monocytes ( $\left.{ }^{*} 103 / \mathrm{UL}\right)$ & $0.143 \pm 0.027$ & $0.223 \pm 0.022$ \\
\hline Number of eosinophils $\left({ }^{*} 103 / \mathrm{UL}\right)$ & $0.107 \pm 0.052$ & $0.055 \pm 0.027$ \\
\hline Number of basophils ( $\left.{ }^{*} 103 / \mathrm{UL}\right)$ & $0.047 \pm 0.023$ & $0.022 \pm 0.014$ \\
\hline Percentage of neutrophils & $28.163 \pm 1.247$ & $23.215 \pm 1.477$ \\
\hline Lymphocyte percentage & $65.807 \pm 1.857$ & $70.335 \pm 1.962$ \\
\hline Monocyte percentage & $3.250 \pm 1.063$ & $4.898 \pm 0.443$ \\
\hline Percentage of eosinophils (\%) & $1.980 \pm 1.094$ & $1.107 \pm 0.539$ \\
\hline Percentage of basophils (\%) & $0.807 \pm 0.430$ & $0.447 \pm 0.286$ \\
\hline
\end{tabular}




\begin{tabular}{lll} 
Number of red blood cells $\left({ }^{*} 106 / \mathrm{UL}\right)$ & $7.650 \pm 0.229$ & $7.343 \pm 0.218$ \\
Hemoglobin concentration $(\mathrm{g} / \mathrm{dl})$ & $111.333 \pm 3.180$ & $109.333 \pm 3.148$ \\
Hematocrit $(\%)$ & $37.833 \pm 1.278$ & $36.767 \pm 1.207$ \\
Mean corpuscular volume $(\mathrm{Fl})$ & $49.467 \pm 1.320$ & $50.067 \pm 0.956$ \\
Mean hemoglobin content $(\mathrm{pg})$ & $14.567 \pm 0.521$ & $14.900 \pm 0.221$ \\
Mean hemoglobin concentration (g/L) & $287.667 \pm 10.868$ & $297.833 \pm 4.708$ \\
RBC distribution width $(\%)$ & $14.633 \pm 0.433$ & $14.983 \pm 0.309$ \\
Platelet count $\left({ }^{*} 103 / \mathrm{UL}\right)$ & $576.667 \pm 101.259$ & $631.667 \pm 85.693$ \\
Mean platelet volume $(\mathrm{FL})$ & $4.933 \pm 0.219$ & $4.917 \pm 0.087$ \\
\hline
\end{tabular}

Data are means $\pm \mathrm{SEM}$, control $(\mathrm{n}=3)$; liquiritin $(\mathrm{n}=6)$; ${ }^{*} \mathrm{P}<0.05$ compared with control mice. 
Supplementary Table 7 : Body weight, organ index, blood chemistry and blood analysis in control or liquiritin-treated female mice by intravenous injection.

\begin{tabular}{|c|c|c|}
\hline & Control-female & Liquiritin-female \\
\hline Body weight, $g$ & $28.867 \pm 0.581$ & $30.283 \pm 0.473$ \\
\hline Brain index, $\%$ & $1.583 \pm 0.041$ & $1.520 \pm 0.035$ \\
\hline Thyroid index, \% & $0.647 \pm 0.034$ & $0.680 \pm 0.042$ \\
\hline Lungs index, $\%$ & $0.590 \pm 0.050$ & $0.612 \pm 0.013$ \\
\hline Thymus index, \% & $0.183 \pm 0.022$ & $0.215 \pm 0.018$ \\
\hline Heart index, \% & $0.427 \pm 0.009$ & $0.428 \pm 0.018$ \\
\hline Liver index, \% & $4.393 \pm 0.170$ & $3.688 \pm 0.054^{* *}$ \\
\hline Spleen index, \% & $0.403 \pm 0.015$ & $0.363 \pm 0.021$ \\
\hline Pancreas index, \% & $0.600 \pm 0.036$ & $0.597 \pm 0.024$ \\
\hline Kidney index, \% & $1.200 \pm 0.055$ & $1.145 \pm 0.037$ \\
\hline Ovary index, \% & $0.090 \pm 0.010$ & $0.127 \pm 0.010$ \\
\hline Uterus index, \% & $0.430 \pm 0.075$ & $0.520 \pm 0.065$ \\
\hline Stomach index, \% & $0.817 \pm 0.048$ & $0.722 \pm 0.032$ \\
\hline Bladder index, $\%$ & $0.070 \pm 0.000$ & $0.065 \pm 0.002$ \\
\hline ALT U/L & $56.133 \pm 5.441$ & $40.400 \pm 2.912^{*}$ \\
\hline AST U/L & $107.4 \pm 12.450$ & $118.350 \pm 2.949$ \\
\hline GLU-God mmol/L & $5.873 \pm 0.779$ & $5.315 \pm 0.772$ \\
\hline TC mmol/L & $2.65 \pm 0.560$ & $2.968 \pm 0.166$ \\
\hline TG mmol/L & $0.617 \pm 0.116$ & $0.740 \pm 0.080$ \\
\hline $\mathrm{TP} \mathrm{g} / \mathrm{L}$ & $55.333 \pm 3.290$ & $61.083 \pm 1.554$ \\
\hline ALB g/L & $30.600 \pm 0.321$ & $34.183 \pm 0.715^{*}$ \\
\hline UA umol/L & $141.4 \pm 56.486$ & $58.583 \pm 2.483$ \\
\hline UREA mmol/L & $2.757 \pm 0.472$ & $1.998 \pm 0.049^{*}$ \\
\hline $\mathrm{CK} \mathrm{U} / \mathrm{L}$ & $442.267 \pm 38.585$ & $439.733 \pm 26.190$ \\
\hline$\alpha-\mathrm{HBDH} \mathrm{U} / \mathrm{L}$ & $28.633 \pm 1.962$ & $32.383 \pm 3.144$ \\
\hline HDL-C mmol/L & $2.317 \pm 0.462$ & $2.627 \pm 0.122$ \\
\hline LDL-C mmol/L & $0.410 \pm 0.076$ & $0.287 \pm 0.034$ \\
\hline LDH U/L & $290.933 \pm 38.479$ & $325.017 \pm 20.649$ \\
\hline ALP U/L & $2.467 \pm 0.674$ & $3.533 \pm 0.314$ \\
\hline T-Bil umol/L & $1.160 \pm 0.096$ & $1.308 \pm 0.062$ \\
\hline Number of leukocytes $\left({ }^{*} 103 / \mathrm{UL}\right)$ & $5.327 \pm 0.280$ & $3.837 \pm 0.686$ \\
\hline Number of neutrophils $\left({ }^{*} 103 / \mathrm{UL}\right)$ & $1.353 \pm 0.246$ & $0.937 \pm 0.229$ \\
\hline Lymphocyte count $\left({ }^{*} 103 / \mathrm{UL}\right)$ & $3.670 \pm 0.156$ & $2.640 \pm 0.432$ \\
\hline Number of monocytes ( $\left.{ }^{*} 103 / \mathrm{UL}\right)$ & $0.197 \pm 0.048$ & $0.188 \pm 0.023$ \\
\hline Number of eosinophils $\left({ }^{*} 103 / \mathrm{UL}\right)$ & $0.080 \pm 0.056$ & $0.052 \pm 0.027$ \\
\hline Number of basophils ( $\left.{ }^{*} 103 / \mathrm{UL}\right)$ & $0.027 \pm 0.018$ & $0.017 \pm 0.012$ \\
\hline Percentage of neutrophils & $25.150 \pm 3.512$ & $22.780 \pm 2.326$ \\
\hline Lymphocyte percentage & $69.340 \pm 5.048$ & $69.998 \pm 1.521$ \\
\hline Monocyte percentage & $3.623 \pm 0.667$ & $5.710 \pm 1.173$ \\
\hline Percentage of eosinophils (\%) & $1.443 \pm 0.931$ & $1.092 \pm 0.568$ \\
\hline Percentage of basophils (\%) & $0.447 \pm 0.294$ & $0.422 \pm 0.259$ \\
\hline
\end{tabular}




\begin{tabular}{lll} 
Number of red blood cells $\left({ }^{*} 106 / \mathrm{UL}\right)$ & $7.123 \pm 0.138$ & $7.485 \pm 0.262$ \\
Hemoglobin concentration $(\mathrm{g} / \mathrm{dl})$ & $109.333 \pm 4.055$ & $107.833 \pm 2.713$ \\
Hematocrit $(\%)$ & $39.100 \pm 0.577$ & $35.900 \pm 1.309$ \\
Mean corpuscular volume (Fl) & $54.933 \pm 0.348$ & $48.050 \pm 1.447$ \\
Mean hemoglobin content $(\mathrm{pg})$ & $15.200 \pm 0.404$ & $14.450 \pm 0.339$ \\
Mean hemoglobin concentration (g/L) & $277.000 \pm 6.245$ & $301.500 \pm 7.261$ \\
RBC distribution width $(\%)$ & $14.867 \pm 0.467$ & $15.733 \pm 0.226$ \\
Platelet count $\left({ }^{*} 103 / \mathrm{UL}\right)$ & $532.667 \pm 42.881$ & $536.333 \pm 66.231$ \\
Mean platelet volume $(\mathrm{FL})$ & $5.100 \pm 0.153$ & $5.050 \pm 0.099$ \\
\hline
\end{tabular}

Data are means \pm SEM, control $(\mathrm{n}=3)$; liquiritin $(\mathrm{n}=6) ;{ }^{*} \mathrm{P}<0.05$ compared with control mice. 
Supplementary Table 8 : Body weight, organ index, blood chemistry and blood analysis in control or liquiritin-treated male mice by intraperitoneal injection.

\begin{tabular}{|c|c|c|c|}
\hline & $\begin{array}{l}\text { Control- } \\
\text { male }\end{array}$ & $\begin{array}{l}\text { Liquiritin- } \\
\text { male }\end{array}$ & $\begin{array}{l}\text { Liquiritin- } \\
\text { male-recovery }\end{array}$ \\
\hline Body weight, $g$ & $35.133 \pm 0.426$ & $34.533 \pm 0.240$ & $34.600 \pm 0.321$ \\
\hline Brain index, \% & $1.243 \pm 0.038$ & $1.307 \pm 0.024$ & $1.320 \pm 0.046$ \\
\hline Thyroid index, \% & $0.770 \pm 0.050$ & $0.703 \pm 0.038^{* *}$ & $0.787 \pm 0.048$ \\
\hline Lungs index, $\%$ & $0.537 \pm 0.012$ & $0.570 \pm 0.040$ & $0.540 \pm 0.035$ \\
\hline Thymus index, \% & $0.150 \pm 0.010$ & $0.220 \pm 0.010^{*}$ & $0.173 \pm 0.003$ \\
\hline Heart index, \% & $0.420 \pm 0.015$ & $0.387 \pm 0.012$ & $0.443 \pm 0.013$ \\
\hline Liver index, \% & $4.607 \pm 0.239$ & $3.907 \pm 0.058$ & $5.847 \pm 0.116^{*}$ \\
\hline Spleen index, \% & $0.267 \pm 0.027$ & $0.417 \pm 0.035$ & $0.343 \pm 0.018$ \\
\hline Pancreas index, \% & $0.567 \pm 0.055$ & $0.610 \pm 0.025$ & $0.817 \pm 0.067$ \\
\hline Kidney index, \% & $1.687 \pm 0.058$ & $1.437 \pm 0.047$ & $1.427 \pm 0.084$ \\
\hline Testis index, \% & $0.683 \pm 0.009$ & $0.617 \pm 0.029$ & $0.663 \pm 0.009$ \\
\hline Epididymis index, \% & $0.143 \pm 0.003$ & $0.143 \pm 0.018$ & $0.183 \pm 0.024$ \\
\hline Stomach index, \% & $0.737 \pm 0.050$ & $0.657 \pm 0.022$ & $0.670 \pm 0.038$ \\
\hline Bladder index, \% & $0.083 \pm 0.015$ & $0.080 \pm 0.010$ & $0.080 \pm 0.010$ \\
\hline ALT U/L & $131.833 \pm 27.310$ & $45.100 \pm 5.856^{*}$ & $57.833 \pm 6.743$ \\
\hline AST U/L & $137.000 \pm 3.555$ & $113.100 \pm 14.755$ & $118.767 \pm 10.810$ \\
\hline GLU-God mmol/L & $3.753 \pm 0.387$ & $3.680 \pm 0.996$ & $9.350 \pm 0.356^{* * *}$ \\
\hline TC mmol/L & $2.970 \pm 0.119$ & $3.750 \pm 0.545$ & $3.320 \pm 0.118$ \\
\hline TG mmol/L & $0.573 \pm 0.047$ & $0.940 \pm 0.126$ & $1.227 \pm 0.172^{*}$ \\
\hline $\mathrm{TP} \mathrm{g} / \mathrm{L}$ & $71.800 \pm 19.310$ & $60.100 \pm 3.600$ & $55.133 \pm 0.617$ \\
\hline ALB g/L & $27.167 \pm 1.097$ & $31.767 \pm 1.330$ & $28.233 \pm 0.524$ \\
\hline UA umol/L & $74.967 \pm 4.101$ & $106.567 \pm 16.136$ & $53.900 \pm 1.504^{* *}$ \\
\hline UREA mmol/L & $2.217 \pm 0.119$ & $1.933 \pm 0.027$ & $2.237 \pm 0.182$ \\
\hline $\mathrm{CK} \mathrm{U/L}$ & $335.200 \pm 72.660$ & $481.600 \pm 53.306$ & $517.767 \pm 25.695$ \\
\hline$\alpha-\mathrm{HBDH}$ U/L & $39.900 \pm 5.900$ & $34.433 \pm 9.089$ & $30.067 \pm 4.784$ \\
\hline HDL-C mmol/L & $2.383 \pm 0.084$ & $2.900 \pm 0.454$ & $2.887 \pm 0.061^{* *}$ \\
\hline LDL-C mmol/L & $0.477 \pm 0.033$ & $0.613 \pm 0.062$ & $0.360 \pm 0.066$ \\
\hline LDH U/L & $443.900 \pm 48.916$ & $433.600 \pm 112.348$ & $314.100 \pm 54.673$ \\
\hline ALP U/L & $3.267 \pm 0.333$ & $2.567 \pm 0.318$ & $5.267 \pm 0.145^{* *}$ \\
\hline T-Bil umol/L & $1.533 \pm 0.194$ & $1.310 \pm 0.140$ & $1.760 \pm 0.068$ \\
\hline Number of leukocytes $\left({ }^{*} 103 / \mathrm{UL}\right)$ & $6.020 \pm 0.652$ & $5.700 \pm 0.495$ & $7.513 \pm 0.615$ \\
\hline Number of neutrophils( $\left({ }^{*} 103 / \mathrm{UL}\right)$ & $1.600 \pm 0.186$ & $2.907 \pm 0.257^{*}$ & $1.607 \pm 0.279$ \\
\hline Lymphocyte count $\left({ }^{*} 103 / \mathrm{UL}\right)$ & $3.890 \pm 0.586$ & $2.190 \pm 0.262$ & $5.543 \pm 0.312$ \\
\hline Number of monocytes $\left({ }^{*} 103 / \mathrm{UL}\right)$ & $0.337 \pm 0.041$ & $0.547 \pm 0.166$ & $0.020 \pm 0.006^{* *}$ \\
\hline Number of eosinophils( $\left({ }^{*} 103 / \mathrm{UL}\right)$ & $0.140 \pm 0.015$ & $0.050 \pm 0.010^{* *}$ & $0.340 \pm 0.080$ \\
\hline Number of basophils $\left({ }^{*} 103 / \mathrm{UL}\right)$ & $0.047 \pm 0.020$ & $0.003 \pm 0.003$ & $0.003 \pm 0.003$ \\
\hline Percentage of neutrophils & $27.093 \pm 4.170$ & $51.470 \pm 5.110^{*}$ & $21.063 \pm 2.056$ \\
\hline Lymphocyte percentage & $64.043 \pm 4.323$ & $38.310 \pm 2.880^{* *}$ & $74.157 \pm 2.703$ \\
\hline Monocyte percentage & $5.613 \pm 0.221$ & $9.257 \pm 2.361$ & $0.250 \pm 0.104^{* * *}$ \\
\hline Percentage of eosinophils(\%) & $2.383 \pm 0.377$ & $0.863 \pm 0.127^{*}$ & $4.500 \pm 0.761$ \\
\hline
\end{tabular}




\begin{tabular}{llll} 
Percentage of basophils (\%) & $0.870 \pm 0.090$ & $0.103 \pm 0.055^{* *}$ & $0.027 \pm 0.018^{* * *}$ \\
$\begin{array}{l}\text { Number of red blood } \\
\text { cells }\left({ }^{*} 106 / \mathrm{UL}\right)\end{array}$ & $7.437 \pm 0.383$ & $7.790 \pm 0.145$ & $7.967 \pm 0.072$ \\
$\begin{array}{l}\text { Hemoglobin concentration (g/dl) } \\
\text { Hematocrit }(\%)\end{array}$ & $104.000 \pm 4.041$ & $114.000 \pm 1.000$ & $111.667 \pm 3.180$ \\
Mean corpuscular volume (Fl) & $46.533 \pm 1.081$ & $38.767 \pm 1.444$ & $35.367 \pm 0.581$ \\
Mean hemoglobin content (pg) & $14.000 \pm 0.404$ & $14.633 \pm 0.133$ & $14.033 \pm 0.273$ \\
$\begin{array}{l}\text { Mean hemoglobin } \\
\text { concentration(g/L) }\end{array}$ & $284.333 \pm 3.930$ & $294.667 \pm 8.743$ & $315.333 \pm 3.756^{* *}$ \\
$\begin{array}{l}\text { RBC distribution width (\%) } \\
\text { Platelet count }\left({ }^{*} 103 / \mathrm{UL}\right)\end{array}$ & $15.533 \pm 0.426$ & $16.967 \pm 0.145^{*}$ & $16.567 \pm 0.780$ \\
Mean platelet & $438.333 \pm 90.381$ & $737.000 \pm 24.880^{*}$ & $771.333 \pm 33.418^{*}$ \\
volume (FL) & $5.333 \pm 0.120$ & $4.933 \pm 0.176$ & $4.700 \pm 0.153^{*}$ \\
\hline
\end{tabular}

Data are means \pm SEM, control $(n=3)$; liquiritin $(n=3)$; liquiritin-recovery $(n=3) ;{ }^{*} \mathrm{P}<0.05$ compared with control mice. 
Supplementary Table 9 : Body weight, organ index, blood chemistry and blood analysis in control or liquiritin-treated female mice by intraperitoneal injection.

\begin{tabular}{|c|c|c|c|}
\hline & $\begin{array}{l}\text { Control- } \\
\text { female }\end{array}$ & $\begin{array}{l}\text { Liquiritin- } \\
\text { female }\end{array}$ & $\begin{array}{c}\text { Liquiritin- } \\
\text { female-recovery }\end{array}$ \\
\hline Body weight, $g$ & $27.800 \pm 0.539$ & $28.733 \pm 0.784$ & $27.800 \pm 0.643$ \\
\hline Brain index, \% & $1.597 \pm 0.064$ & $1.533 \pm 0.038$ & $1.670 \pm 0.040$ \\
\hline Thyroid index, \% & $0.613 \pm 0.038$ & $0.550 \pm 0.040$ & $0.697 \pm 0.042$ \\
\hline Lungs index, $\%$ & $0.600 \pm 0.021$ & $0.623 \pm 0.003$ & $0.600 \pm 0.012$ \\
\hline Thymus index, \% & $0.203 \pm 0.024$ & $0.170 \pm 0.038$ & $0.223 \pm 0.049$ \\
\hline Heart index, \% & $0.433 \pm 0.009$ & $0.407 \pm 0.018$ & $0.443 \pm 0.024$ \\
\hline Liver index, \% & $3.847 \pm 0.103$ & $3.930 \pm 0.139$ & $4.747 \pm 0.075^{* *}$ \\
\hline Spleen index, \% & $0.370 \pm 0.040$ & $0.473 \pm 0.043$ & $0.457 \pm 0.035$ \\
\hline Pancreas index, \% & $0.630 \pm 0.086$ & $0.763 \pm 0.033$ & $1.023 \pm 0.107^{*}$ \\
\hline Kidney index, \% & $1.137 \pm 0.038$ & $1.160 \pm 0.059$ & $1.260 \pm 0.062$ \\
\hline Ovary index, \% & $0.107 \pm 0.003$ & $0.117 \pm 0.017$ & $0.120 \pm 0.010$ \\
\hline Uterus index, \% & $0.550 \pm 0.125$ & $0.460 \pm 0.031$ & $0.727 \pm 0.111$ \\
\hline Stomach index, \% & $0.853 \pm 0.029$ & $0.827 \pm 0.027$ & $0.780 \pm 0.025$ \\
\hline Bladder index, \% & $0.070 \pm 0.000$ & $0.070 \pm 0.000$ & $0.070 \pm 0.000$ \\
\hline ALT U/L & $70.500 \pm 24.807$ & $91.167 \pm 45.701$ & $35.433 \pm 3.453$ \\
\hline AST U/L & $106.733 \pm 5.491$ & $97.667 \pm 9.491$ & $104.567 \pm 4.200$ \\
\hline GLU-God mmol/L & $4.027 \pm 0.499$ & $4.707 \pm 0.624$ & $8.417 \pm 0.205^{* * *}$ \\
\hline $\mathrm{TC} \mathrm{mmol} / \mathrm{L}$ & $2.360 \pm 0.070$ & $2.727 \pm 0.171$ & $2.150 \pm 0.074$ \\
\hline TG mmol/L & $0.553 \pm 0.116$ & $0.600 \pm 0.032$ & $1.087 \pm 0.232$ \\
\hline $\mathrm{TP} \mathrm{g} / \mathrm{L}$ & $61.067 \pm 1.562$ & $56.133 \pm 0.328^{*}$ & $52.300 \pm 2.031^{*}$ \\
\hline ALB g/L & $32.400 \pm 1.457$ & $32.967 \pm 0.291$ & $27.933 \pm 1.068$ \\
\hline UA umol/L & $100.867 \pm 9.870$ & $144.033 \pm 27.929$ & $51.200 \pm 3.772^{* *}$ \\
\hline UREA mmol/L & $2.300 \pm 0.154$ & $1.967 \pm 0.064$ & $2.130 \pm 0.127$ \\
\hline CK U/L & $256.967 \pm 69.036$ & $226.933 \pm 30.633$ & $446.233 \pm 103.245$ \\
\hline$\alpha-\mathrm{HBDH} \mathrm{U} / \mathrm{L}$ & $36.033 \pm 2.862$ & $25.333 \pm 2.946$ & $27.933 \pm 1.068$ \\
\hline $\mathrm{HDL}-\mathrm{C} \mathrm{mmol} / \mathrm{L}$ & $2.147 \pm 0.192$ & $2.080 \pm 0.200$ & $1.840 \pm 0.000$ \\
\hline LDL-C mmol/L & $0.450 \pm 0.026$ & $0.440 \pm 0.025$ & $0.323 \pm 0.038$ \\
\hline LDH U/L & $376.767 \pm 31.053$ & $315.467 \pm 42.721$ & $250.400 \pm 53.029$ \\
\hline ALP U/L & $2.333 \pm 0.788$ & $2.667 \pm 0.120$ & $13.667 \pm 2.206^{* *}$ \\
\hline T-Bil umol/L & $1.377 \pm 0.068$ & $0.947 \pm 0.175$ & $1.653 \pm 0.136$ \\
\hline Number of leukocytes ( $\left.{ }^{*} 103 / \mathrm{UL}\right)$ & $4.767 \pm 1.188$ & $5.107 \pm 0.775$ & $6.267 \pm 1.109$ \\
\hline Number of neutrophils( $\left({ }^{*} 103 / \mathrm{UL}\right)$ & $0.920 \pm 0.388$ & $2.013 \pm 0.475$ & $0.970 \pm 0.142$ \\
\hline Lymphocyte count $\left({ }^{*} 103 / \mathrm{UL}\right)$ & $3.603 \pm 0.814$ & $2.380 \pm 0.194$ & $4.873 \pm 0.943$ \\
\hline Number of monocytes $\left({ }^{*} 103 / \mathrm{UL}\right)$ & $0.227 \pm 0.015$ & $0.637 \pm 0.182$ & $0.013 \pm 0.007^{* *}$ \\
\hline Number of eosinophils $\left({ }^{*} 103 / \mathrm{UL}\right)$ & $0.0133 \pm 0.007$ & $0.070 \pm 0.035$ & $0.403 \pm 0.083$ \\
\hline Number of basophils ( $\left.{ }^{*} 103 / \mathrm{UL}\right)$ & NA & $0.013 \pm 0.009$ & $0.003 \pm 0.003$ \\
\hline Percentage of neutrophils & $16.943 \pm 5.317$ & $38.483 \pm 3.150^{*}$ & $15.790 \pm 2.024$ \\
\hline Lymphocyte percentage & $77.073 \pm 3.560$ & $47.507 \pm 3.438^{* *}$ & $77.363 \pm 1.396$ \\
\hline Monocyte percentage & $5.697 \pm 1.983$ & $12.290 \pm 2.581$ & $0.263 \pm 0.104$ \\
\hline Percentage of eosinophils (\%) & $0.250 \pm 0.098$ & $1.457 \pm 0.812$ & $6.473 \pm 1.175^{* *}$ \\
\hline
\end{tabular}


Percentage of basophils (\%)

Number of red blood cells

$\left({ }^{*} 106 /\right.$ UL $)$

Hemoglobin concentration

$(\mathrm{g} / \mathrm{dl})$

Hematocrit (\%)

Mean corpuscular volume (Fl)

Mean hemoglobin content (pg)

Mean hemoglobin concentration

$(\mathrm{g} / \mathrm{L})$

RBC distribution width (\%)

Platelet count $\left({ }^{*} 103 / \mathrm{UL}\right)$

Mean platelet volume (FL)

$\begin{array}{lll}0.033 \pm 0.020 & 0.263 \pm 0.166 & 0.100 \pm 0.075 \\ 6.993 \pm 0.515 & 7.493 \pm 0.074 & 7.643 \pm 0.038\end{array}$

$98.000 \pm 11.930 \quad 113.667 \pm 0.333 \quad 107.000 \pm 2.082$

$33.067 \pm 4.103 \quad 38.667 \pm 0.437 \quad 34.867 \pm 1.133$

$46.900 \pm 2.916 \quad 51.633 \pm 1.081 \quad 45.634 \pm 1.485$

$13.933 \pm 0.845 \quad 15.167 \pm 0.133 \quad 13.967 \pm 0.318$

$296.667 \pm 2.848 \quad 294.000 \pm 4.163 \quad 307.000 \pm 7.234$

$15.500 \pm 0.379 \quad 16.467 \pm 0.145 \quad 16.333 \pm 0.233$

$612.667 \pm 42.049 \quad 613.000 \pm 48.952 \quad 597.000 \pm 25.813$

$4.733 \pm 0.233 \quad 4.833 \pm 0.176 \quad 4.667 \pm 0.145$

Data are means \pm SEM, control $(n=3)$; liquiritin $(n=3)$; liquiritin-recovery $(n=3)$; ${ }^{*} \mathrm{P}<0.05$ compared with control mice. 